\title{
Erratum to: Soil Fertility and the Impact of Exotic Invasion on Microbial Communities in Hawaiian Forests
}

\author{
Jenny Kao-Kniffin • Teri C. Balser
}

Published online: 26 May 2012

(C) Springer Science+Business Media, LLC 2012

Erratum to: Microb Ecol

DOI 10.1007/s00248-007-9323-1

The erratum shows the corrected figure from p.59 of KaoKniffin and Balser. 2008. Microbial Ecology. 56:55-63 $<$ DOI 10.1007/s00248-007-9323-1>. The graph titles for Figure 2 a-e were omitted in the print edition. The titles now indicate lipid relative abundances for: a) Monounsaturated, b) Branched chain, c) Hydroxy, d) Cyclopropyl, e) Saprotrophic fungi, and f) AM fungi microbial guilds.

The online version of the original article can be found at http://dx.doi.org/ $10.1007 / \mathrm{s} 00248-007-9323-1$.

\footnotetext{
J. Kao-Kniffin $(\bowtie)$

Department of Horticulture, Cornell University,

134a Plant Science Building,

Ithaca, NY 14853, USA

e-mail: jtk57@cornell.edu

T. C. Balser

Division of Land Resources, Gaylord Nelson Institute for Environmental Studies, University of Wisconsin, Madison, WI 53706, USA

T. C. Balser

Department of Soil Science, University of Wisconsin, 1525 Observatory Drive,

Madison, WI 53706-1299, USA
} 

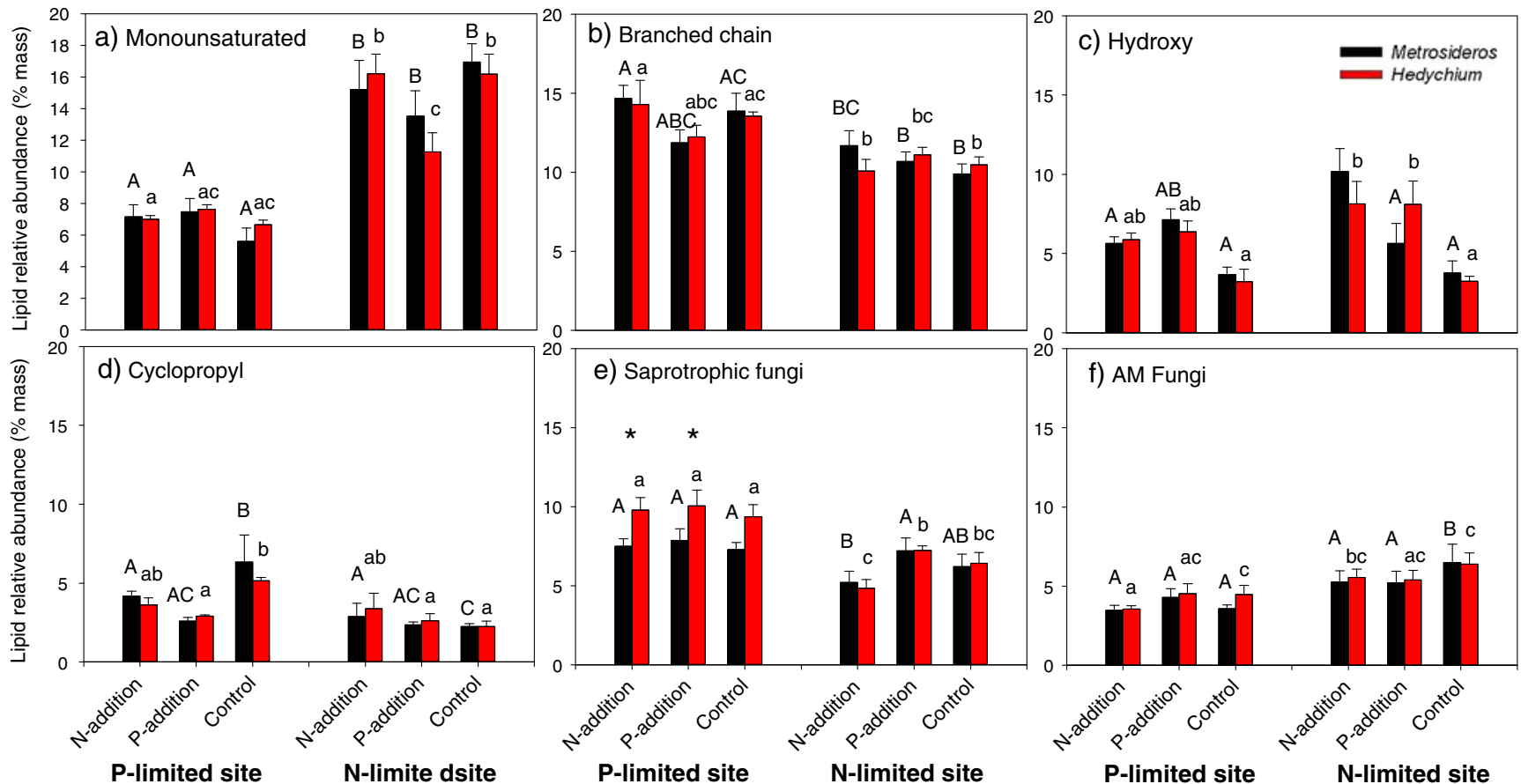

Fig. 2 Microbial lipid relative abundance (mass percentage) of indicator guilds (means $\pm 1 \mathrm{SE}$ ). Microbial lipid relative abundance from soils collected under the native Metrosideros are represented by black bars and those collected under the invasive Hedychium are represented by red bars. Bars with capital case letters indicate means comparisons among Metrosideros samples (bars with the same capital letters are not

significantly different), whereas bars with lowercase letters indicate means comparisons among Hedychium samples (bars with the same lowercase letters are not significantly different; Fisher's LSD, $\mathrm{P}<0.05$ ). An asterisk above two bars indicates a significant difference between the two plant species 